It does not seem likely, however, that the investigation would lead to interesting physical results, because this lind of motion is essentially dynamically unstable.

Towards the end of the same article there occurs the following passage :-

"The old idea that a ship (or more correctly a totally im. mersed body, such as a fish) encountered a mysterious resistance in addition to the mere friction of the molecules on its sides, is now known to have been a pure delusion."

This statement appears to me either erroneous or very misleading. The resistances to the motion of a ship have been classified under three heads, viz., wave-making resistance, eddymaking resistance, and surface-friction. ${ }^{1}$ For a totally-immersed body the wave-making resistance is non-existent, but Mr. Preston would appear only to take notice of the last of the three. Now whilst for a body with "fair lines," such as a fish, the eddy-making resistance may be small, yet if the lines are not fair it may be very large. Thus a fish leaves scarcely any wake, whilst an oar leaves a very great amount of disturbance.

Helmholtz, Kirchhoff, ${ }^{2}$ and Lord Rayleigh ${ }^{3}$ have made some interesting hydrodynamical investigations on the resistance suffered by a vane exposed to a current, on the hypothesis that in the wake of the vane there is dead water, separated from the moving water by surfaces of finite slip.

It has been already noticed that such a motion is dynamically unstable, but there is in many respects a remarkable accordance between the resistance as determined by this theory and that found experimentally, ${ }^{4}$ so that it seems probable that the actual stable motion of flow, with eddies in the wake, does not differ very much from the theoretically unstable motion, with dead water in the wake. It will be noticed that this theory of resistance, which gives approximate results for bodies with very bad lines, such as flat vanes, actually entirely neglects surface-friction, to which Mr. Preston's statement would seem to refer the whole resistance.

Trinity College, Cambridge, May 27

\section{The Inevitable Test for Aurora}

In reference to Prof. Prazzi Smyth's courteous criticism of our communication to the Royal Society on the aurora borealis, we regret that we are unable to say whether the critical citron line, to which he directs attention, was present or not in the spectra of the electric discharges in atmospheric air from which we deduced the probable heights of auroral displays. The experiments quoted were made without reference to the aurora, and this particular line was consequently not sought for, nor indeed have many measurements been made of the spectra of discharges in atmospheric air, on account of the time required and consequent great consumption of the life of the battery which such observations entail.

73, Portland Place, W., May 29

WARREN DE LA RU

\section{Cloud Classification}

THERE is a proverbial objection to "looking a gift-horse in the mouth," and M. Poey's Cloud Book is such a valuable addition to the scanty literature on the subject that it would be highly ungracious to make captious objections to his views. On the other hand, M. Poëy, when he differs from others, puts forward his views with such fairness and courtesy that I believe he would be the last man to deprecate full discussion.

Allow me then to put in a plea for certain old public servants, that they should neither be cashiered altogether, nor transported to strange regions, without full examination into their character and their merits.

First, then, for the stratus.

M. Poëy-happy man!-has carried on his observations under tropical skies and in the clear atmosphere of Paris. Had his lot been cast on the clays and gravels of the London basin I venture to think that he would have regarded the "stratus" with more respect, if with no increase of affection. He would have had frequent opportunities of observing it-at times resting entirely on the ground, ${ }^{5}$ at others rising with a clearly

${ }^{I}$ Froude, Proc. of Roy, Inst., December, 1876 .

"Math Vorlesuncen," 2Ist and and lectures.

3 Fhit. Mag., December, 1876 .

4 In particular Lord Rayleigh's investigation throws light on the theory of the balanced rudder.

5 Howard's Essay says, "its inferior surface commonly" (not "invariably" or "necessarily") "rests on the earth :or water." P. 7 , Edit. 1868 defined lower and upper isurface, a few feet (or even inches) from the earth, cutting the taller trees in a horizontal line, leaving their tops and bottoms free, and then being gradually dissipated, to be absorbed in the warmer air or to form cumuli at a higher elvation. He conld hardly have failed to recognise it as a clear and distinct variety of cloud, the lowest in altitude of all the family, but none the less a member of it. If every cloud which has contact with our baser earth is to be cashiered on that account, what will become of M. Poëy's own cumulus on Plate XV. ? Every mountaineer knows to his cost that if he happens to be on the mountain where such a cumulus is resting, he will be enveloped in a fog undistinguishable from what he finds on the Thames marshes.

Whether, on the other hand, it is desirable to use the term "stratus" for clouds in a totally different sky-region, which differ both in their origin and their nature from the true "stratus," is a question too long to be fully discussed here.

Next with regard to the nimbus.

M. Poëy's view appears to be that Howard's term applies to an isolated shower-cloud, and is unsuitable for a rain-cloud overspreading the sky. After careful reading of M. Poëy's remarks on the "pallium," and comparing them with Howard's description of the "nimbus," I entirely fail to see where lies sufficient difference to consign the "nimbus" to oblivion; and I can only imagine that M. Poëy has taken his idea ${ }^{\mathrm{I}}$ of what Howard meant almost entirely from the illustration, without noticing that Howard first describes the forming and behaviour of the cloud overhead in words curiously similar to those which Poëy himself uses for his "pallium," and then says, "But we see the nature of this process more perfectly in viewing a distant shower in profile." This clearly shows that the illustration was only chosen as the easiest form in which the cloud, vel nubium congeries, could be depicted, while the context guards completely against the name being limited to an isolated shower-cloud.

It would occupy to much space to place the descriptions of the two savants side by side, but I think that any one who will take the trouble to read the two together can hardly fail to see that Howard's "nimbus" fulfils all that Poëy describes as the rain-discharging cloud, including the upper "veil," 2 or pallium of cirrus, the lower "sheet," 3 or "pallium" of cumulus, and the "lower clouds arriving from the wind ward," which "move under this sheet and are successively lost in it " (Howard, p. II ; compare Poëy, Plate XII.). In fact, to use an expression frequently employed in the discussion of patents, you can take the description of the one inventor and "read it on to" the drawing of the other, or vice versâ.

M. Poëy's term "pallium" is certainly expressive, and will probably make itself a home in cloud terminology; but it appears after all only to mean that a certain modification overspreads the whole or a large part of the sky (compare Howard, p. II), and does not by any means cover that combination of clouds which produces rain ("nimbus.")

I must leave it to a future time or to other pens to discuss the merits of the "cumulo-stratus," and pass on to examine shortly M. Poëy's views about the "cumulus." The Rev. W. C. Ley, in his review of M. Poëy's work, in your pages, has already pointed out the illogical nature of the author's repeated remark that the "cumulus" only exists in the horizon, forgetting that a cloud which is on the horizon of one place must be in the zenith of another. Now I venture to suggest that this curionsiydistorted mental view affects M. Poëy's classification far more than appears at first sight. If clouds are considered not objectively according to their whole form and structure, but subjectively as they present themselves to an individual observer, we naturally need new modifications as the clouds are viewed in different positions. Are not many of the clonds which M. Poëy calls "fracto-cumulus" simply "cumuli" viewed from beneath? Just as (to borrow a simile from Mr. Ley) an elm-tree seen from beneath presents a spreading, ragged edge, and shows the blue sky through its interstices, whereas on the horizon it appears compact, rounded, and sharply defined.

May I add a practical suggestion as to the popular terms proposed by M. Poëy on p. 39 ? These terms are put forward as an alternative to the scientific Latin names, for the use of nonscientific observers, who may be of great service in collecting information at out-stations where no trained meteorologist is at hand. It is therefore all-important that they should be as short,

I See Poëy, p. 33.

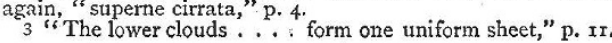

